\title{
Entrevista - Jörn Rüsen Algumas ideias sobre a interseção da meta-história e da didática da história
}

\author{
Marília Gago*
}

Entrevista realizada por e-mail, dias 1, 2 e 28 de março de 2016.

Tradução: Tradioma, Porto, Portugal.

Jörn Rüsen, Professor do Kulturwissenschaftliches Institut (Instituto de Estudos Avançados em Humanidades) em Essen, Alemanha, recebeu o título de Doutor Honoris Causa pela Universidade de Brasília (Brasil) e pela Universidade de Lund (Suécia). É Professor Emérito da Universidade de Witten/ Herdecke (Alemanha) e recebeu a Ordem de Mérito do Estado de Northrhine-Westfalia da República Federal da Alemanha. Foi professor convidado no Instituto para Estudos Avançados em Humanidades e em Ciências Sociais na Universidade Nacional de Taiwan, Investigador Responsável do Projeto "Humanismo na era da globalização - um diálogo intercultural entre humanidade, cultura e valores" no Kulturwissenschaftliches Institut em Essen, Alemanha, e presidente desse instituto.

História Académica e História Escolar - dois mundos diferentes ou dois mundos que podem/devem dialogar?

A história académica e a história na escola são discursos diferentes, mas muito entrelaçados. Ambas pertencem à cultura histórica de uma sociedade. A cultura histórica é o local de orientação cultural da vida humana ao longo do tempo. Representa o passado com vista à compreensão do presente e às expectativas de futuro. Nas sociedades modernas ocorreram algumas diferenciações e especializações. Uma é a fundação de estudos históricos como uma disciplina académica. Aqui, a principal questão é a obtenção de conhecimentos sólidos

\footnotetext{
* Doutora em Educação, área de metodologia do ensino de História e Ciências Sociais, Universidade do Minho (UM). Centro de Investigação Transdisciplinar "Cultura, Espaço e Memória”, Faculdade de Letras da Universidade do Porto (CITCEM-FLUP). Porto, Portugal. gago.marilia@gmail.com
} 
alicerçados numa investigação metodicamente regulada. Outra [questão] é a criação de educação histórica na escola. Aqui, a questão principal é ensinar história de uma forma tal que os estudantes se tornem competentes para a cultura histórica da sua sociedade. Ambos os discursos são realizados por especialistas: académicos e professores. Ambos os discursos criaram reflexões sobre o trabalho prático dos profissionais: teoria da história (Historik em alemão, meta-history em inglês), por um lado, e didática da história, por outro lado.

Ambos os discursos e disciplinas partilham questões fundamentais:

1) em primeiro lugar, claro, a "história" como uma síntese de eventos do passado e a sua representação no presente, além disso;

2) a consciência histórica como o processo mental para interpretar o passado como história;

3) aprender história como um processo organizado de desenvolvimento da consciência histórica (na academia, ao ensinar aos estudantes as competências de investigação; na escola, ao ensinar os modos básicos do pensamento histórico);

4) a orientação histórica como a função prática do conhecimento histórico; e

5) a argumentação racional como o modo de comunicação.

Mas também ambos os discursos seguem diferentes intenções: o discurso de e acerca dos estudos históricos lidando com os procedimentos de obtenção e representação de conhecimento histórico sólido, enquanto o discurso da didática da história está mais focalizado nos procedimentos do ensino e da aprendizagem histórica.

O primeiro discurso, meta-história, responde à pergunta o que é a história. Aqui referimo-nos à filosofia da história ou à epistemologia do pensamento histórico. Para confirmar e estabilizar o caráter académico dos estudos históricos desde a sua constituição como uma disciplina académica, a meta-história tematiza as regras de investigação. Encontramos aqui uma longa tradição de metodologia de investigação. Adicionalmente, tematiza a representação histórica pela historiografia. De forma esquemática, os princípios da meta-história podem ser representados como uma matriz disciplinar de estudos históricos em Rüsen (2015, p.72 - tradução da entrevistadora): 


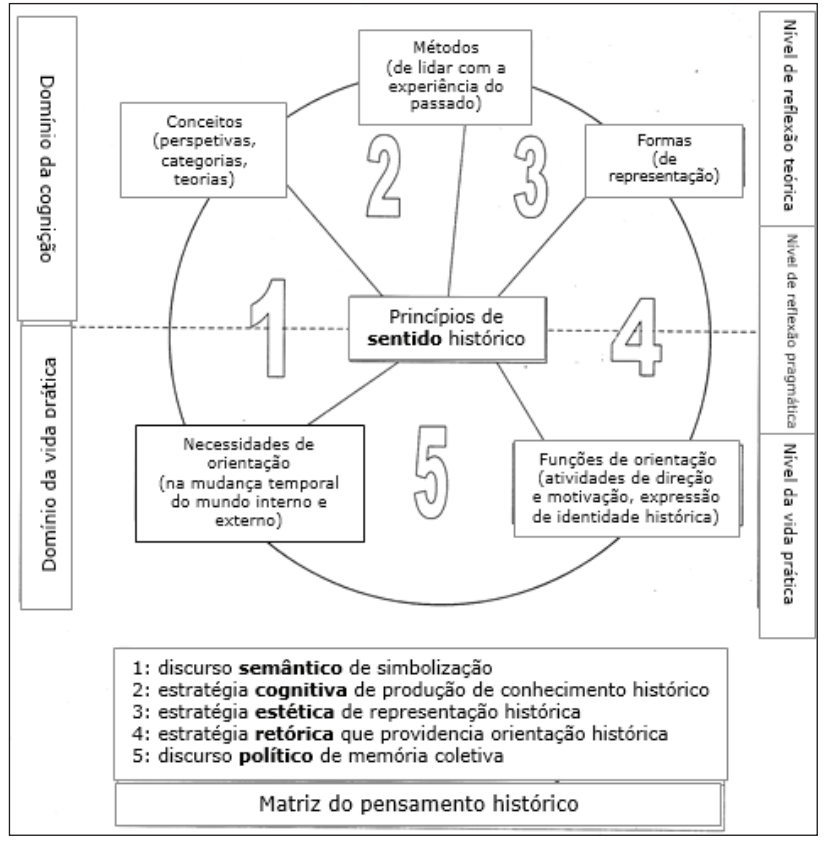

A didática da história partilha o interesse na apresentação à sua audiência de uma ideia clara acerca do que é a história. Apropria-se desta ideia da meta-história. Mas o foco não é o modo de produção de conhecimento através da investigação e a sua apresentação historiográfica, está focalizada em direcionar o processo de aprendizagem da história de modo organizado (principalmente através do ensino da história na escola). A aprendizagem histórica é um processo mental em que as competências necessárias são capturadas para orientar a sua própria vida através da consciência histórica que foi previamente dada pela cultura histórica da sociedade de cada um. Tal situação consiste em quatro diferentes capacidades (habilidades) que estão sistematicamente inter-relacionadas e são interdependentes:

- a capacidade de vivenciar a experiência histórica;

- a capacidade de interpretação de experiência histórica;

- a capacidade de usar a experiência histórica interpretada (conhecimento histórico) para orientar a sua própria vida no quadro de uma ideia 
corroborada empiricamente no decurso do tempo das vidas humanas - esta orientação inclui um conceito de identidade histórica;

- a capacidade de motivar as nossas próprias atividades de acordo com a ideia do nosso lugar nas mudanças que ocorrem no tempo.

Assim, a principal intenção da didática da história é a educação, ou de forma mais elaborada e ambiciosa: Bildung, isto é, ser competente na orientação histórica e na capacidade de partilhar os discursos públicos na cultura histórica (das suas) respetivas sociedades. Em analogia com a matriz disciplinar de estudos históricos, também pode ser esquematizada uma matriz da didática da história.

Matriz disciplinar da Didática da História (segundo Jörn Rüsen)

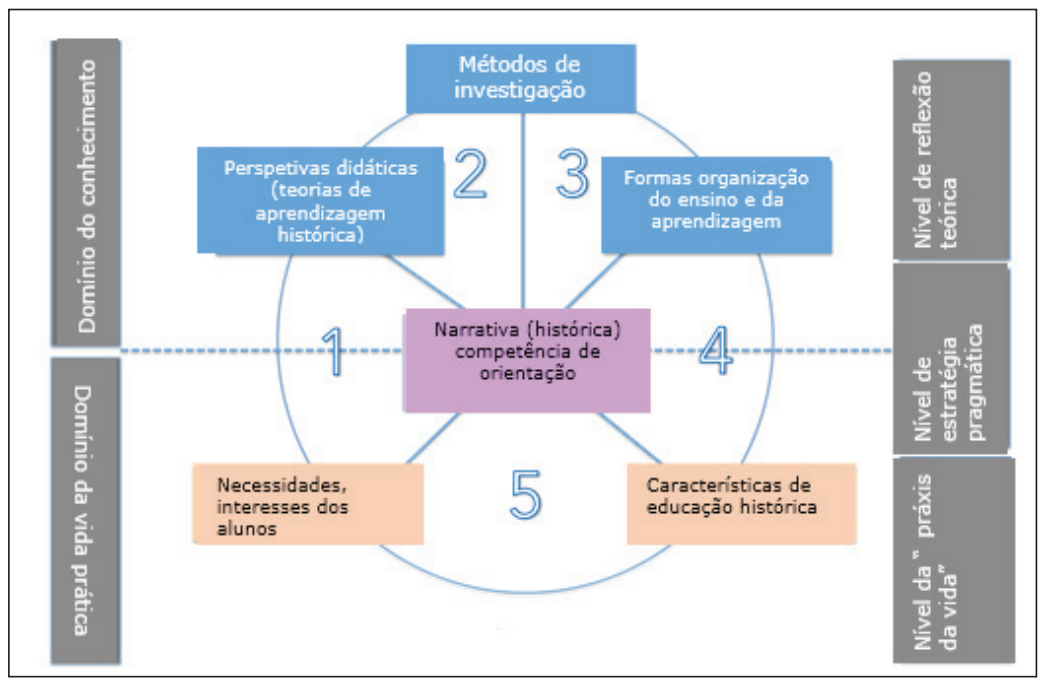

(Fonte: Demantowsky, 2016 - tradução da entrevistadora)

Como já referi, a meta-história e a didática da história estão fortemente inter-relacionadas e dependentes uma da outra. A partir do olhar da meta-história a didática da história apropria-se da ideia de história e de pensamento histórico (e das suas peculiaridades e função no contexto da vida cultural). A explicação da estrutura cognitiva e a forma narrativa do pensamento histórico têm uma especial importância.

Inversamente, a didática da história é importante para a meta-história, na medida em que garante a interiorização na estrutura mental da consciência 
histórica, dos elementos não cognitivos (por exemplo, emoções) durante o processo de formação de significado acerca do passado como história, numa função educativa básica na lógica do pensamento histórico e na ideia básica de Bildung (cultura da subjetividade) dada pela história na vida humana.

\section{Didática da história e Epistemologia - intercontribuições, que tipo de relações?}

A Epistemologia proporciona uma reflexão introspetiva na lógica do pensamento histórico. A epistemologia foi desenvolvida formalmente como filosofia da história, quando os historiadores profissionais a recusaram por esta contradizer a forma deles obterem conhecimento histórico sólido a partir do tratamento metódico das fontes. O seu foco estava centrado na análise da peculiaridade do conhecimento histórico explicando a diferença fundamental entre este e o conhecimento produzido pelas ciências naturais. Nesta tradição, o pensamento histórico era entendido como orientado pelo princípio de compreensão e individualização; em contrapartida, as ciências naturais eram entendidas como orientadas pelo princípio da explicação e generalização.

O culminar da peculiaridade do pensamento histórico é o narrativismo. Este enfatiza o facto de a história ser sempre apresentada sob a forma de uma narração. Consequentemente, a lógica é a de contar uma narrativa. Mas as narrativas também são contadas fora do domínio da cultura histórica. Assim, cabe-nos colocar a questão: o que torna uma narrativa histórica? Para mim, a resposta mais convincente a esta questão é a sua referência à experiência do passado. Esta referência é introduzida de forma bastante elaborada na investigação histórica. A partir das relíquias do passado (fontes) ganha um conhecimento sólido sobre o que aconteceu no passado e onde, quando, e por que razão aconteceu. Para a construção deste conhecimento os eventos do passado têm de ter uma ordem temporal; e esta ordem tem de ser estruturada pela ideia de uma inter-relação significativa entre o passado e o presente (com uma perspetiva para o futuro). Nesta perspetiva, que é moldada por esta ideia, os eventos do passado alcançam o seu significado histórico sob a forma de narrativa.

A narrativa produz uma história para o presente a partir das ocorrências e eventos do passado. Isto pode ser feito de formas fundamentalmente diferentes, dependentes de princípios diferentes do significado histórico. Numa concetualização ideal-tipológica pode distinguir-se quatro tipos de significado histórico, de formação do significado da experiência do passado: tradicional, exemplar, genético e crítico. 


\begin{tabular}{|c|c|c|c|c|}
\hline 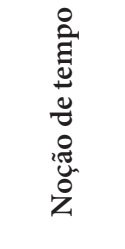 & 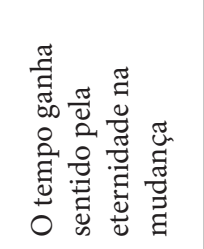 & 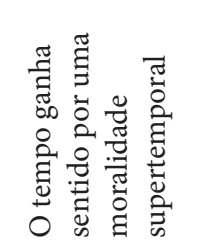 & 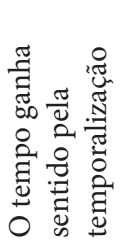 & 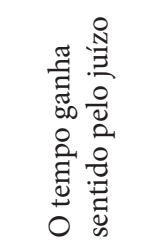 \\
\hline 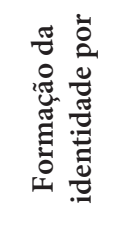 & 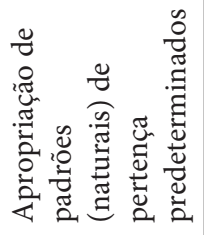 & 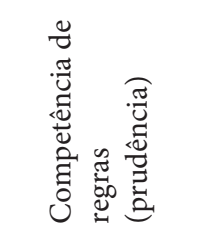 & 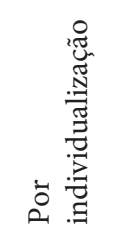 & 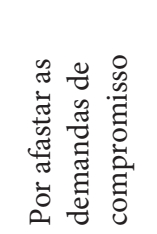 \\
\hline 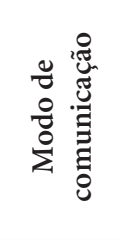 & 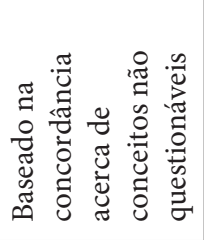 & 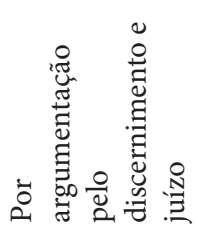 & 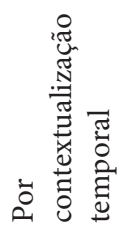 & 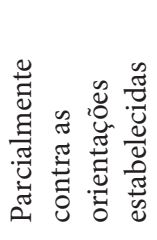 \\
\hline 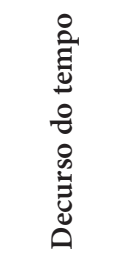 & 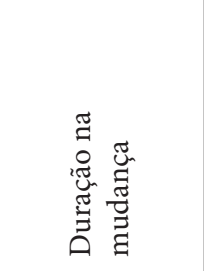 & 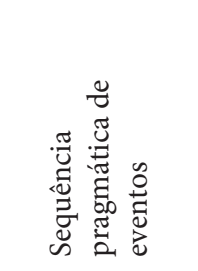 & 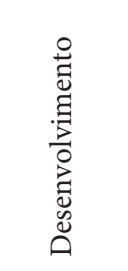 & 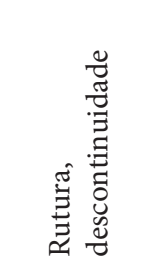 \\
\hline 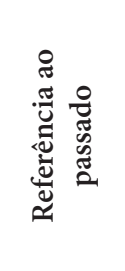 & 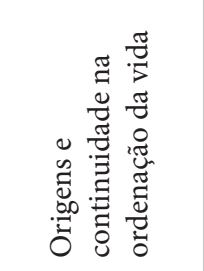 & 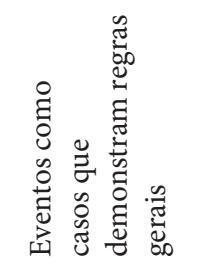 & 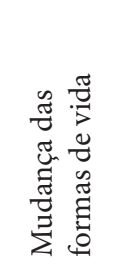 & 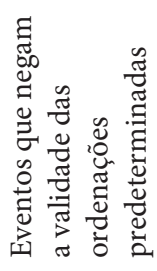 \\
\hline 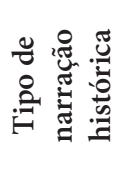 & 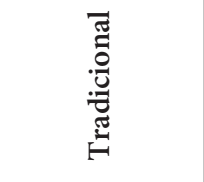 & 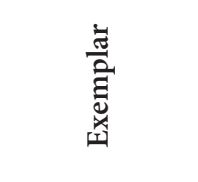 & : & 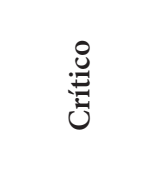 \\
\hline
\end{tabular}


Esta tipologia (e com ela a sua epistemologia) é muito importante para a didática da história, já que os estudantes têm de aprender as estruturas básicas do pensamento histórico, as suas diferentes formas lógicas, as suas inter-relações e a ordenação do seu desenvolvimento. Isto é bastante fácil, já que os tipos ocorrem na vida diária assim como em formas mais elaboradas de fazer história. Esta aprendizagem deveria ser acompanhada pelo ensino histórico "normal" na escola: ao tratar eventos históricos de forma que eles obtenham significado para o presente e deveria (e poderia) ser refletida a sua perspetiva futura, conforme Rüsen (2012).

Como poderia a História fazer sentido hoje para os estudantes, em linha com a orientação temporal (presente e futuro)?

Para ensinar história é necessário alicerçá-la numa conexão entre o presente e o seu futuro e o passado. Esta relação pode ser concetualizada (na meta-história) por uma antropologia histórica. Torna o passado compreensível ao colocar os eventos e as suas sequências temporais num quadro de ferramentas de interpretação, que é moldado por princípios antropológicos universais (como dominação, trabalho, comunicação social, formação de significado acerca do mundo, inter-relações entre a espécie humana e a natureza). Adicionalmente a estes princípios antropológicos universais tem de ser usada uma ideia de mudança temporal para compreender a peculiaridade das formas de vida humana no decurso do tempo. A antropologia histórica é a síntese das características universais da vida humana e da ideia de mudança e desenvolvimento. Ambos são tematizados em meta-história. Ao ensinar história na escola tem-se de enfatizar esta síntese de forma que os estudantes encontrem uma similitude comum e básica nas formas de vida humana e diferenças básicas devidas às variáveis e alteradas circunstâncias. A mudança temporal tem de ser interpretada atendendo a uma ideia de desenvolvimento, que relacione o passado com o presente ("o ainda não") e o presente com o passado ("o já não"). A questão da identidade histórica tem de ser colocada nesta inter-relação. A questão "Quem somos nós?" visará uma resposta complexa: "identidade" como um produto de desenvolvimentos passados e uma projeção do futuro mediando simultaneamente experiências e normas, condições e esperanças. 
A meta-história fornece um conceito de identidade histórica, e a didática da história transforma-a num conceito de desenvolvimento da consciência histórica através da aprendizagem.

Ensino da História e Humanismo: o Humanismo é o objetivo do ensino da História ou deve estar presente no ensino da história?

O Humanismo é a moldura básica de criação do significado histórico. Baseia-se nos desenvolvimentos históricos reais (nas diferentes culturas) que foram moldados por normas fundamentais de autoconhecimento humano (como a ideia da dignidade humana). Não existe e/ou humanismo na história e no ensino. O Iluminismo desenvolveu a ideia de história como um processo universal de educação da espécie humana (Lessing, Schiller). Esta ideia tem de ser aplicada à nossa experiência histórica de desumanidade. Através desta aplicação a característica do humanismo não desaparecerá, mas modificar-se-á ao adquirir características de uma elevada ambiguidade e servirá como um impulso urgente na cultura através da ideia de história como um processo de humanizar a humanidade. Esta característica ambivalente da humanidade e a demanda de humanizar a espécie humana deveriam ser realizadas no ensino e aprendizagem histórica. A didática da história deveria dar a si própria uma forma humanística. Assim poder-se-ia fazer face ao desafio da comunicação intercultural na nossa era da globalização (Rüsen; Laass, 2009; Rechmuth; Rüsen; Sarhan, 2012; Kozlarek; Rüsen; Wolff, 2012; Rüsen; Spariosu, 2012; Rüsen, 2013).

\section{Tolerância e arrependimento são a face da Memória ou da História?}

Para mim, "história" e "memória" não são alternativas. Ambos os termos são termos fundamentais de discursos diferentes, o académico, no qual os estudos históricos refletem acerca da importância e do efeito na orientação cultural da vida humana, e um discurso crítico emergente após a "viragem cultural" nas humanidades. Aqui a história é caracterizada por ser distante da vida prática, como um refúgio de conhecimento acerca do passado sem uma relação inerente com os problemas de orientação da vida social. Esta justaposição é enganadora. Ignora completamente o discurso sobre a consciência histórica na didática da história e as tendências intrínsecas da cognição histórica resultantes da investigação académica que contribui para a cultura histórica do seu tempo. 
O discurso da memória enfatiza o enorme poder da memória coletiva na cultura histórica. Assim, este tem um importante impacto no ensino e na aprendizagem histórica. Mas não desenvolveu esse impacto numa teoria específica de didática. Além disso, não compreendeu a importância das perspetivas futuras nas referências da atualidade em relação ao passado, e falta-lhe um critério fundamental de significado histórico, nomeadamente criticismo.

Assim, gostaria de colocar os temas "tolerância" e "arrependimento" numa teoria de cultura histórica que agregando história e memória e analise a consciência histórica.

O que é a cultura histórica? É o epítome daquelas orientações da vida humana em que o passado desempenha um papel essencial. Estas orientações foram produzidas pela consciência histórica humana. As suas atividades constituem cultura histórica e realiza-se de formas muito distintas, por exemplo, em monumentos, memoriais, museus, estudos históricos, filmes históricos, comemorações públicas, feriados nacionais, ensino da história na escola, literatura histórica, historiografia profissional e popular. A cultura histórica também inclui as relações privadas com o passado, por exemplo, memórias pessoais, narrativas familiares sobre correlações intergeracionais entre o presente e o passado (Seixas, 2004; Karlsson, 2011; 2011a).

Não existe vida humana sem memórias históricas. Elas estão presentes em todos os domínios da cultura. A cultura histórica está, portanto, manifesta em diferentes dimensões. As mais importantes são a política, a estética e a cognitiva. Numa argumentação mais complexa podem distinguir-se sete dimensões: estética, retórica, política, cognitiva, moral, didática, religiosa, e a dimensão da visão do mundo e da ideologia. As dimensões estão conectadas de diferentes formas, de diferentes pontos de vista e de diferente validade sendo eficazes dentro de si próprias. Esses critérios de validade podem ser:

- coerência formal na dimensão estética;

- poder de convicção na dimensão retórica;

- legitimidade na dimensão política;

- verdade na dimensão cognitiva;

- valores na dimensão moral;

- obtenção de competência histórica na dimensão didática; 
- redenção na dimensão religiosa;

- coerência ideológica na visão do mundo.

Como atitude do comportamento humano, a tolerância está profundamente enraizada na cultura histórica. Aqui está uma questão de experiência histórica. Pode ser vista como um resultado importante da história moderna das ideias e pertence às normas básicas da sociedade civil moderna. Como tal, é um fator normativo na criação do significado histórico, e, portanto, decididamente, uma questão na meta-história e na didática da história. É usada para criticar o etnocentrismo no pensamento histórico. Confronta a diferença cultural com a ideia de equidade e promove a atitude normativa para reconhecer as diferenças culturais no pensamento histórico. Pertence ao sistema de valores do humanismo, atribuindo a cada ser humano a dignidade de ser um fim em si mesmo e não apenas um meio para o fim dos outros (Kant, 1785, p.65). Agora, eu digo: o Homem e genericamente qualquer ser racional existe como um fim em si mesmo e não meramente como um meio que seja usado arbitrariamente por isto ou por aquilo, mas todas as suas ações, estejam relacionadas consigo próprio ou com outros seres racionais, estas devem ser sempre vistas como um fim. Assim, existe a demanda do criticismo como uma ideia inerente de reconhecimento. A violação da dignidade humana é uma exclusão do reconhecimento intercultural de diferenças culturais. Na didática da história a tolerância é um dos objetivos mais importantes da aprendizagem. Tem de ser tratada no contexto de formação de identidade histórica e de domesticar ou civilizar atitudes etnocêntricas da mente humana.

$O$ arrependimento ou o luto estabeleceu-se na cultura histórica sobretudo sob a forma de memória pública e não tanto como atividade cognitiva. Ainda não se tornou um princípio estabelecido de formação de significado histórico. Mas penso que é necessário introduzir esse princípio na maioria, se não em todos, dos domínios do pensamento histórico (inclusive nos estudos históricos). Encontro a razão para este desenvolvimento desejável na necessidade de fazer face às experiências traumáticas de desumanidade, crimes contra a humanidade e genocídio na história contemporânea.

Todas estas experiências são experiências de desistência de humanidade. Enquanto os historiadores assumirem uma humanidade comum com as pessoas do passado e não se colocarem a eles próprios fora da espécie humana tal como a conhecemos até agora (Braidotti, 2013), têm de abordar esta perda de 
humanidade para si próprios. Se perderem esta abordagem da alteração pós-humana nas humanidades, teremos que lidar com uma perda na mente dos próprios historiadores. Aqui a sua identidade fundamental como seres humanos é colocada em causa. Poderíamos diagnosticar uma perda de nós próprios ao lidar com a desumanidade na história.

Para nos reconciliarmos com essa perda, a cultura humana desenvolveu o processo mental de luto. O luto, portanto, deveria tornar-se um elemento efetivo da cultura histórica (Rüsen, 2004; 2008).

A didática da história ainda não abordou esta questão. Mas é o momento de confrontar os estudantes com a experiência da perda da humanidade de cada um. Ao compreender e comemorar os eventos de destruição radical da humanidade, quando se ensina e aprende história, os estudantes têm de experienciar e adquirir habilidade de luto no domínio da sua consciência histórica. Os dias de luto comum pertencem à cultura histórica de muitos povos e nações. Este luto deveria tornar-se um elemento da consciência histórica em todas e para além das mudanças de gerações.

\section{REFERÊNCIAS}

BRAIDOTTI, Rosi. The Posthuman. Cambridge: Polity Press, 2013.

DEMANTOWSKY, Marko. A History/Memory Matrix for History Education. 2016. Disponível em: http://public-history-weekly.oldenbourg-verlag.de/4-2016-6/a -historymemory-matrix-for-history-education/\#comment-5789; Acesso em: 30 maio 2016.

KANT, Immanuel. Fundamental Principles of the Metaphysic of Morals. 1.ed. Riga: Johann Friedrich Hartknoch, 1785.

KARLSSON, Klas-Göran. Historical Consciousness - the fundament of Historical thinking and History teaching. In: NORDGREN, Kenneth; ELIASSON, Per; RÖNNQVIST, Carina. The Process of History Teaching. 1.ed. Karlstad: Karlstad University Press, 2011.

Processing Time - on the manifestation and activation of historical consciousness. In: BJERK, Helle; LEZ, Claudia; THORSTENSEN, Eric. Historizing the using of the past: Scandinavian perspectives on History Culture, Historical Consciousness and Didactics of History related to World War II. 1.ed. Bielefeld: Transcript, 2011a.

KOZLAREK, Oliver; RÜSEN, Jörn; WOLFF, Ernst (Eds.) Shaping a Humane World: 
Civilizations, Axial Times, Modernities, Humanisms. 1ed. Bielefeld: Transcript, 2012.

REICHMUTH, Stefan; RÜSEN, Jörn; SARHAN, Aladdin (Eds.) Humanism and Muslim Culture: Historical Heritage and Contemporary Challenges. 1.ed. Göttingen: V\&R unipress, 2012.

RÜSEN, Jörn. Emotional Forces un Historical Thinking: Some Metahistorical Reflections and the Case of Mourning. Historein - A Review of the past and other stories, n.8, pp. 41-53, 2008.

. Forming Historical Consciousness - Towards a Humanistic History Didactics. In: NORDGREN, Kenneth; ELIASSON, Per; RÖNNQVIST, Carina. The Process of History Teaching. 1.ed. Karlstad: Karlstad University Press, 2011.

. History, narrations, interpretation, orientation. 1.ed. New York: Berghahn Books, 2005.

. Humanismo e Didática da História. 1.ed. Curitiba: W.A. Editores, 2015.

. Teoria da história: uma teoria da história como ciência. 1.ed. Curitiba: Ed. UFPR, 2015.

. Tradition: A Principle of Historical Sense Generation and its Logic and Effect in Historical Culture. History and Theory - Theme Issue: Tradition, Middletown: Wesleyan University, v.51, n.4, p.45-59, 2012.

. Trauma and Mourning in Historical Thinking. Journal of Interdisciplinary Studies in History and Archeology, New York: New York University, v.1, n.1, p.1021, 2004.

. (Ed.) Approaching Humankind: Towards an Intercultural Humanism. 1.ed. Göttingen: V\&R unipress, 2013.

RÜSEN, Jörn; LAASS, Henner (Eds.) Humanism in Intercultural Perspective: Experiences and Expectations. 1.ed. Bielefeld: Transcript, 2009.

RÜSEN, Jörn; SPARIOSU, Michai (Eds.) Exploring Humanity: Intercultural Perspectives on Humanism. 1.ed. Göttingen: V\&R unipress, 2012.

SEIXAS, Peter. Theorising historical consciousness. 1.ed. Toronto: Toronto University Press, 2004.

Entrevista recebida em 1 de abril de 2016. Aprovada em 30 de maio de 2016. 